\title{
Preparation of a germole-containing $\pi$-conjugated polymer by the Te-Li exchange reaction of a tellurophene-containing polymer
}

\author{
Feng Zheng ${ }^{1}$, Sia-Er Tan', Yuki Yanamoto', Naoki Shida (1)', Hiroki Nishiyama', Shinsuke Inagi ${ }^{1}$ and Ikuyoshi Tomita (1)
}

\begin{abstract}
The synthesis and optoelectronic functions of a germole-containing $\pi$-conjugated polymer prepared by the reaction of a lithiated polymer precursor are described. A regioregular organometallic polymer having 1,4-dilithio-1,3-butadiene and 9,9-dioctylfluorene-2,7-diyl units was generated by the reaction of a tellurophene-containing polymer having a number-average molecular weight $\left(M_{n}\right)$ and molecular weight distribution $\left(M_{w} / M_{n}\right)$ of 5900 and 1.9, respectively, with $n$-butyllithium (2.4 equiv) at -78 to $-60^{\circ} \mathrm{C}$ for $3 \mathrm{~h}$. The prepared lithiated polymer was reacted with dimethylgermanium dichloride ( 1.5 equiv) at $-60^{\circ} \mathrm{C}$ to ambient temperature for $12 \mathrm{~h}$ in tetrahydrofuran to produce a $\pi$-conjugated polymer possessing 1,1-dimethylgermole-2,5-diyl units in $76 \%$ yield $\left(M_{n}=4400\right.$ and $\left.M_{w} / M_{n}=1.7\right)$. The absorption maximum and onset of the obtained polymer were observed at 465 and $535 \mathrm{~nm}$, respectively, in the UV-vis spectrum, from which the optical band gap of the polymer was estimated to be $2.31 \mathrm{eV}$. In the photoluminescence spectrum, the obtained polymer exhibits green fluorescence with an emission maximum of $547 \mathrm{~nm}$ and a quantum yield of 0.04 . The chemical interaction of the dimethylgermole-containing $\pi$-conjugated polymer with fluoride was also examined in terms of the changes observed in the UV-vis absorption spectra.
\end{abstract}

\section{Introduction}

$\pi$-Conjugated polymers are attractive materials for the construction of functional organic optoelectronic devices $^{1-4}$. According to the theoretical calculations carried out by Lagowski and coworkers, the incorporation of heteroatoms into the main chain of $\pi$-conjugated polymers provides us the chance to alter the energy levels of the highest occupied molecular orbital (HOMO) and lowest unoccupied molecular orbital (LUMO). For example, polymers containing heteroles of group 14 elements, such as poly(silole)s, are predicted to possess both low LUMO and high HOMO levels that would be suitable for both $\mathrm{n}$ - and $\mathrm{p}$-type semiconducting materials ${ }^{5}$. Silolecontaining polymers have been prepared by Yamaguchi, Tamao, and their coworkers, and the excellent electron-

Correspondence: Ikuyoshi Tomita (tomita@echem.titech.ac.jp)

'Department of Chemical Science and Engineering, School of Materials and Chemical Technology, Tokyo Institute of Technology, Nagatsuda-cho

4259-G1-9, Midori-ku, Yokohama 226-8502, Japan transporting properties of these polymers were demonstrated in organic EL devices. This unique electronic function is explained by the low-lying LUMO energy levels due to $\sigma^{*}-\pi^{*}$ orbital interactions ${ }^{6,7}$. Stannolecontaining polymers have also been prepared by Staubitz and coworkers and independently by us by using highly tin-selective Stille coupling reactions and by the transformation of organotitanium polymers, respectively. As also expected from the theoretical calculations, these polymers exhibited low-lying LUMO energy levels due to $\sigma^{* *}-\pi^{*}$ orbital interactions ${ }^{8,9}$.

Germole derivatives, heteroles containing the germanium atom (Ge), are also reported to possess low-lying LUMO energy levels and narrow energy band gaps that are comparable to those of the silole and stannole derivatives ${ }^{10}$. Although germole-containing $\pi$-conjugated materials are also attractive for many optoelectronic applications, within the knowledge of the authors, only one previous synthetic work has been reported by Tilley 
and coworkers in which germole-containing polymers were prepared by the nickel-mediated cross-coupling polymerization of germole-containing monomers prepared from zirconacycle intermediates. Nevertheless, the properties of germole-containing polymers have not yet been fully demonstrated ${ }^{11}$. Since the size of the elements would affect the intermolecular packing of the ring systems, the properties of the germole might be different from those of the silole and stannole. In addition, due to d-block contraction, the electronegativity of Ge is larger than that of $\mathrm{Si}$ and much closer to that of $\mathrm{C}$, which reduces the polarization of $\mathrm{C}-\mathrm{Ge}$ bonds ${ }^{12,13}$.

In the course of our studies on the synthesis and transformations of regioregular organotitanium polymers $^{14-19}$, which are obtained by the reaction of diynes and a low-valent titanium complex, we anticipated that germole-containing $\pi$-conjugated polymers are also obtained by transformation with germanium-containing electrophilic reagents. In our attempts, however, the efficiency of the transformation was not sufficient to carry out the polymer reactions. Very recently, we reported the synthesis of highly reactive organolithium polymers via the $\mathrm{Te}-\mathrm{Li}$ exchange reaction of tellurophene-containing polymers. That is, tellurophenecontaining polymers, which were prepared by the postelement transformation of organotitanium polymers ${ }^{20}$, were subjected to the tellurium-lithium exchange process to generate organolithium polymers ${ }^{21,22}$. The highly reactive nature of the organolithium polymers was demonstrated in part by the reaction with tributyltin chloride to produce tributyltin-substituted $\pi$-conjugated polymers, which have seldom been accessible by transformation of organotitanium polymers. Because of the higher reactivity of the organolithium polymers compared to that of the organotitanium polymers, we expect that unprecedented $\pi$-conjugated polymers containing more versatile elements and functional groups would be accessible by means of the post-element transformation technique. To establish a new synthetic route and to produce attractive germole-containing $\pi$-conjugated polymers, we describe herein the reaction of an organolithium polymer generated by the $\mathrm{Te}-\mathrm{Li}$ transformation of a tellurophene-containing polymer with dimethylgermanium dichloride. The optoelectronic features of the germole-containing polymer are also described to reveal its potential applications.

\section{Materials and methods Materials}

2,5-Diphenyltellurophene (1) and a tellurophene-2,5diyl-containing polymer (4) were prepared via organotitanium intermediates as previously described ${ }^{20}$. $n$-Butyllithum (a $1.6 \mathrm{M}$ hexane solution) was obtained from Sigma-Aldrich, and dimethylgermanium dichloride
$\left(\mathrm{Me}_{2} \mathrm{GeCl}_{2}\right)$ was obtained from Tokyo Chemical Industry. Tetrahydrofuran (THF) was dried over sodium benzophenone ketyl and distilled under nitrogen. The reactions were carried out under argon, and all reagents for precipitation and analyses were used as received.

\section{Apparatus}

Nuclear magnetic resonance spectra were obtained on a JEOL ECP300 spectrometer in $\mathrm{CDCl}_{3}$ (300 and $75 \mathrm{MHz}$ for ${ }^{1} \mathrm{H}$ NMR and ${ }^{13} \mathrm{C}$ NMR, respectively). Tetramethylsilane was used as an internal standard for ${ }^{1}$ H NMR spectra. Size exclusion chromatography (SEC) measurements were performed on a Shimadzu LC-10AS liquid chromatograph equipped with Tosoh TSK-gel GMHHR-M tandem columns using chloroform $\left(\mathrm{CHCl}_{3}\right)$ as the eluent at $35^{\circ} \mathrm{C}$. Polystyrene standards were used for the calibration. Ultraviolet-visible (UVvis) absorption spectra and photoluminescence (PL) spectra were measured in $\mathrm{CHCl}_{3}$ on a Shimadzu UV3100PC and a Shimadzu RF-6000PC spectrometer. Fourier transform infrared (FT-IR) spectra were measured on a Shimadzu IRSpirit spectrophotometer. Highresolution mass spectra (HR-MS) were obtained on a JEOL JMS-SX102A spectrometer. Electrochemical measurements were recorded on a VersaSTAT3 (Princeton Applied Research) potentiostat using a platinum (Pt) disk working electrode $(d=1.6 \mathrm{~mm}$, BAS, Japan), a spiral Pt wire auxiliary electrode, and a silver (Ag) wire reference electrode under a nitrogen stream. The molecular orbital density functional theory (DFT) calculations were performed by using the Becke's threeparameter Lee-Yang-Parr hybrid (B3LYP) functional and the $6-31 \mathrm{G}(\mathrm{d})$ basis set in the Gaussian16 program package $^{23}$.

\section{Experimental procedures \\ Synthesis of 1,1-dimethyl-2,5-diphenylgermole (3)}

To a $20 \mathrm{~mL}$ two-necked test tube containing $1(0.040 \mathrm{~g}$, $0.12 \mathrm{mmol})$ and THF $(5.0 \mathrm{~mL})$, was added $n$-butyllithium (2.4 equiv, $1.6 \mathrm{M}, 0.18 \mathrm{~mL}, 0.29 \mathrm{mmol}$ ) at $-78{ }^{\circ} \mathrm{C}$, and the mixture was gradually warmed to $-60^{\circ} \mathrm{C}$. After stirring at $-60^{\circ} \mathrm{C}$ for $3 \mathrm{~h}$, the obtained lithiated intermediate (2) was reacted with $\mathrm{Me}_{2} \mathrm{GeCl}_{2}$ (1.5 equiv, $0.031 \mathrm{~g}, 0.18 \mathrm{mmol}$ ), and the mixture was slowly warmed to ambient temperature and stirred for an additional $12 \mathrm{~h}$. Then, the resulting reaction mixture was poured into water $(10 \mathrm{~mL})$, the organic layer was collected, and the aqueous phase was extracted three times with dichloromethane $\left(\mathrm{CH}_{2} \mathrm{Cl}_{2}\right)$ (total $20 \mathrm{~mL}$ ). After drying the combined organics over anhydrous sodium sulfate, the volatile fractions were evaporated under reduced pressure, and the residue was purified by silica gel column chromatography (eluent: hexane) to give 1,1-dimethyl-2,5-diphenylgermole (3) in $83 \%$ yield $(0.031 \mathrm{~g}, 0.10 \mathrm{mmol})$ (Figs. S1 and S2). 
Synthesis of 1,1-dimethylgermole-2,5-diyl-containing $\pi$-conjugated polymer (6)

A 1,1-dimethylgermole-2,5-diyl-containing polymer (6) was prepared by the same method described above for the synthesis of 3 . A tellurophene-containing $\pi$-conjugated polymer (4: $0.034 \mathrm{~g}, 0.060 \mathrm{mmol}$ units, number-average molecular weight $\left(M_{\mathrm{n}}\right)=5900$, molecular weight distribution $\left.\left(M_{\mathrm{w}} / M_{\mathrm{n}}\right)=1.9\right)$ was used as a starting material, and the product $(6)$ was isolated in $76 \%$ yield $(0.025 \mathrm{~g}$, $0.046 \mathrm{mmol}$ units) as a red solid by precipitation into hexane $\left(M_{\mathrm{n}}=4400, M_{\mathrm{w}} / M_{\mathrm{n}}=1.7\right.$, by SEC) (Figs. S3 and S4).

\section{Results and discussion}

Synthesis of germole derivative and germole-containing polymers

As a model study of the polymer reaction, we first investigated the transformation of 1,4-diphenyl-1,4-dilithio-1,3-butadiene (2), which was obtained from 2,5diphenyltellurophene (1), into 1,1-dimethyl-2,5-diphenylgermole (3) by the use of $\mathrm{Me}_{2} \mathrm{GeCl}_{2}$. That is, the lithiated intermediate (2) was prepared in situ from 2,5diphenyltellurophene (1) with $n$-butyllithium (2.4 equiv) from -78 to $-60^{\circ} \mathrm{C}$ in tetrahydrofuran (THF) for $3 \mathrm{~h}$ and was then subjected to the reaction with $\mathrm{Me}_{2} \mathrm{GeCl}_{2}$ (1.5 equiv) from $-60^{\circ} \mathrm{C}$ to ambient temperature for $12 \mathrm{~h}$ without isolation (Scheme 1). As a result, the desired 1,1dimethyl-2,5-diphenylgermole (3) was obtained in $83 \%$ yield as a pale yellow solid by silica gel column chromatography. The quantitative efficiency of this reaction can be supported by the ${ }^{1} \mathrm{H}$ NMR spectrum of the products obtained in the reaction of lithiated intermediate (2) and $\mathrm{Me}_{2} \mathrm{GeCl}_{2}$ without purification. That is, no peaks for the starting tellurophene or 1,4-diphenyl-1,3-butadiene were observed at 7.8 and $6.9 \mathrm{ppm}$, respectively, indicating that the conversion of the reaction is quantitative and that side reactions such as simple protonation do not occur. The observed integral ratio between the aromatic protons and the methyl protons (12.6:6.0) is consistent with the calculated value (12.0:6.0), which would suggest that the NMR yield of the product is high enough (>95\%) (Fig. S5).

Likewise, the regioregular reactive polymer having 1,4dilithio-1,3-butadiene-1,4-diyl repeating units (5) was obtained by the reaction of the $\pi$-conjugated tellurophene-containing polymer $\left(4: M_{\mathrm{n}}=5900, M_{\mathrm{w}} / M_{\mathrm{n}}\right.$ $=1.9$ ) with $n$-butyllithium (2.4 equiv) from -78 to $-60^{\circ} \mathrm{C}$ in THF for $3 \mathrm{~h}$ (Scheme 2) and was then subjected to the reaction with $\mathrm{Me}_{2} \mathrm{GeCl}_{2}$ (1.5 equiv) from $-60^{\circ} \mathrm{C}$ to ambient temperature for $12 \mathrm{~h}$ to produce a 1,1-dimethylgermole-2,5-diyl-containing polymer (6). Consequently, the germole-containing polymer $\left(6: M_{\mathrm{n}}=4400\right.$, $\left.M_{\mathrm{w}} / M_{\mathrm{n}}=1.7\right)$ was obtained in $76 \%$ yield as a red solid by precipitation into hexane and was soluble in common organic solvents such as THF, toluene, dichloromethane $\left(\mathrm{CH}_{2} \mathrm{Cl}_{2}\right)$, and $\mathrm{CHCl}_{3}$. The structure of $\mathbf{6}$ could be determined from its ${ }^{1} \mathrm{H}$ NMR spectrum. In the ${ }^{1} \mathrm{H}$ NMR spectrum of 6, peaks attributable to the methyl (a), methylene (b), and aromatic protons (c) are observable at $0.5-0.6,1.8-2.0$, and 7.3-7.7 ppm, respectively, with a peak intensity ratio (6.0:4.0:8.1) that is in good accordance with that for the expected structure (6.0:4.0:8.0) (Fig. 1).

\section{Optical properties}

In the UV-vis absorption spectrum of $\mathbf{3}$ taken in THF, the absorption maximum $\left(\lambda_{\max }\right)$ was observed at $379 \mathrm{~nm}$. The emission maximum $\left(E_{\max }\right)$ of $\mathbf{3}$ was observed at $454 \mathrm{~nm}$ in its PL spectrum. These values are almost comparable to those of 1,1-dimethyl-2,5-diphenylsilole $\left(\lambda_{\max }=376 \mathrm{~nm}, E_{\max }=463 \mathrm{~nm}\right)$ as described by Tamao and coworkers (Fig. 2) ${ }^{21}$. It is of note that $\mathbf{3}$ exhibits absorption at a lower energy region than does the starting tellurophene (1), 2,5-diphenylthiophene ${ }^{17}$, and 2,5diphenylselenophene ${ }^{17}$ due to the presence of the $\sigma^{*}-\pi^{*}$ orbital interaction in the dimethylgermole unit. In addition, the higher quantum yield of $\mathbf{3}(\Phi=0.33)$ than of 1,1dimethyl-2,5-diphenylsilole $(\Phi=0.29)$ and $1 \quad(\Phi=0)$ would provide a chance for its applications in organic fluorescence materials. In the UV-Vis absorption spectrum of 6 taken in THF, $\lambda_{\max }$ was observed at $465 \mathrm{~nm}$, which is bathochromically shifted by $86 \mathrm{~nm}$ compared with that of the model compound (3). The clear bathochromic shift indicates the effective extension of $\pi$ conjugation along the backbone of the germolecontaining polymer. Moreover, it was observed that the UV-vis absorption spectrum of $\mathbf{6}$ measured in film was slightly different from that measured in $\mathrm{CHCl}_{3}$, indicating the presence of intermolecular interactions, such as $\pi-\pi$ stacking interactions ${ }^{24}$. The PL spectrum of $\mathbf{6}$ was obtained in THF by excitation at the wavelength of its

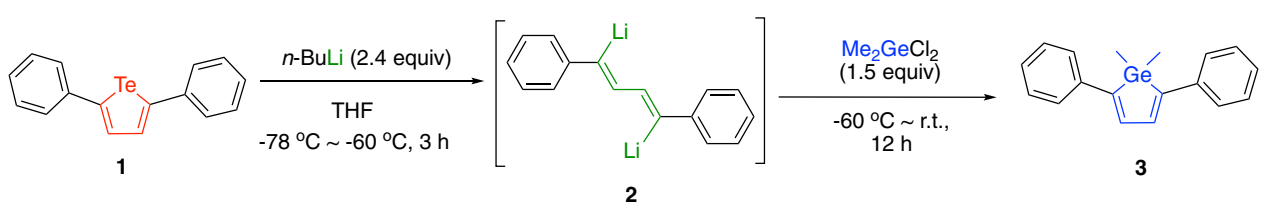

Scheme 1 Synthetic route of $\mathbf{3}$. 

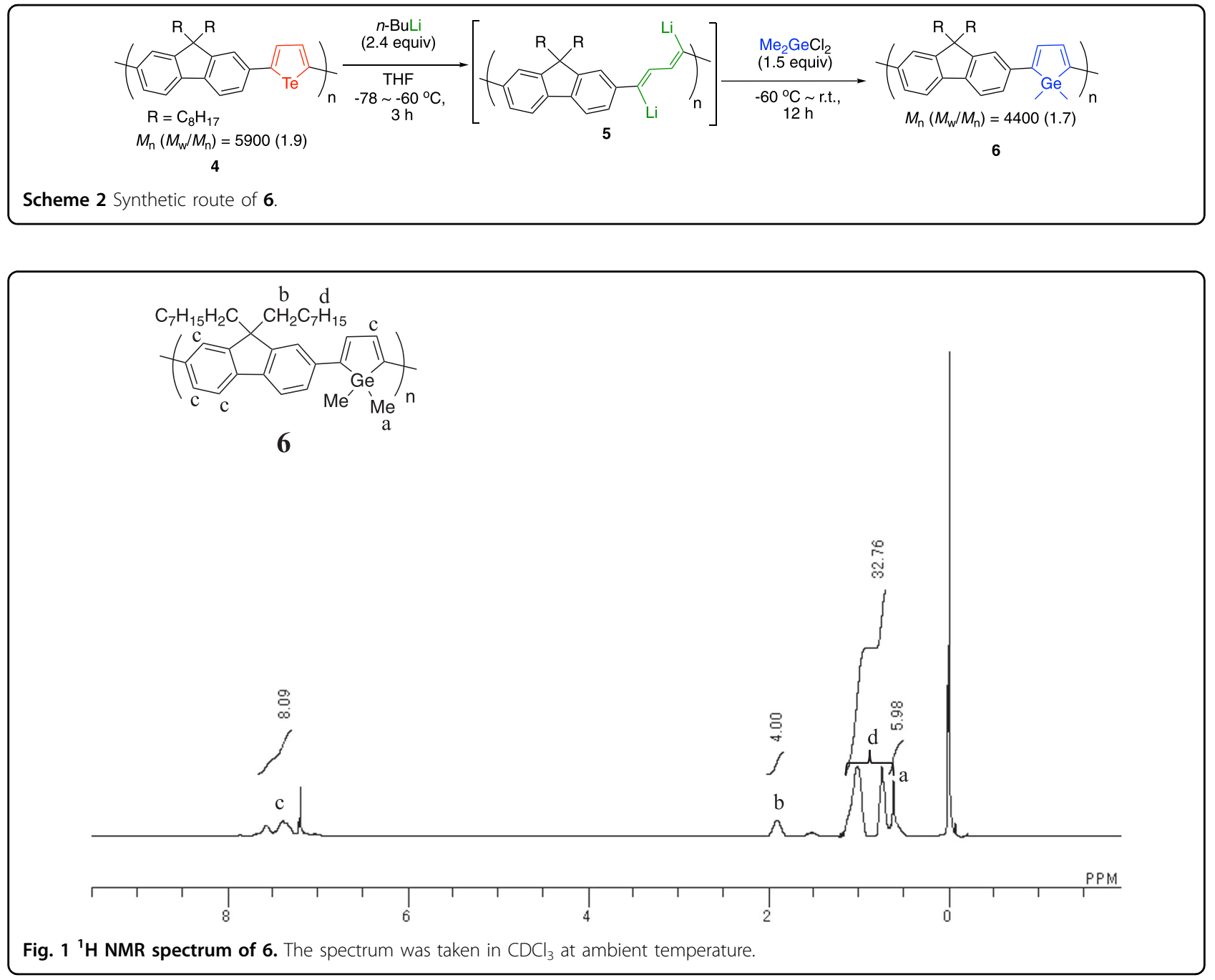

$\lambda_{\max }(465 \mathrm{~nm})$, in which 6 exhibits green fluorescence with an emission maximum of $547 \mathrm{~nm}$. The quantum yield of $\mathbf{6}$ was determined to be 0.04 .

\section{Chemical stability}

The germole-containing polymer (6) was found to be stable enough under basic conditions. For example, no change was observed in its UV-vis or photoluminescence spectra by mixing a THF solution of $\mathbf{6}$ with an aqueous solution of $\mathrm{NaOH}(1.0 \mathrm{M})$ at ambient temperature for $4 \mathrm{~h}$ (Fig. 3a). In contrast, 6 was found not to be stable under acidic conditions. That is, a clear hypsochromic shift of the UV-vis absorption peak was observed by mixing its THF solution with an aqueous solution of $\mathrm{HCl}(1.0 \mathrm{M})$ at ambient temperature, where $\lambda_{\max }$ shifted from 465 to $344 \mathrm{~nm}$. Notably, the fluorescence color of 6 changed from green to blue within 5 min under the same acidic conditions (Fig. 3b).

To understand the decomposition process of the germole-containing polymer (6), the model compound, 1,1-dimethyl-2,5-diphenylgermole (3), was subjected to acidolysis under the same conditions. As a result, a hypsochromic shift of the UV-vis absorption peak was likewise observed, where $\lambda_{\max }$ shifted from 379 to $325 \mathrm{~nm}$. The products obtained after acidolysis were found to contain 1,4-diphenyl-1,3-butadiene, as determined from the ${ }^{1} \mathrm{H}$ NMR spectrum of the resulting mixture (Fig. S6).

\section{Electrochemical properties}

The electrochemical properties of $\mathbf{3}$ were evaluated from cyclic voltammetry (CV) analysis in an acetonitrile solution (Fig. S7). From the onset oxidation potential $\left(E_{\mathrm{ox}}\right)$ observed in the CV measurement and the optical band gap calculated from the absorption onset $\left(\lambda_{\text {onset }}\right)$ in the UV-vis spectrum, the highest occupied molecular orbital (HOMO) and the lowest unoccupied molecular orbital (LUMO) energy levels of 3 were estimated to be -5.50 and $-2.50 \mathrm{eV}$, respectively. The HOMO energy level of 3 was slightly higher than that of 1,1-dimethyl-2,5- 

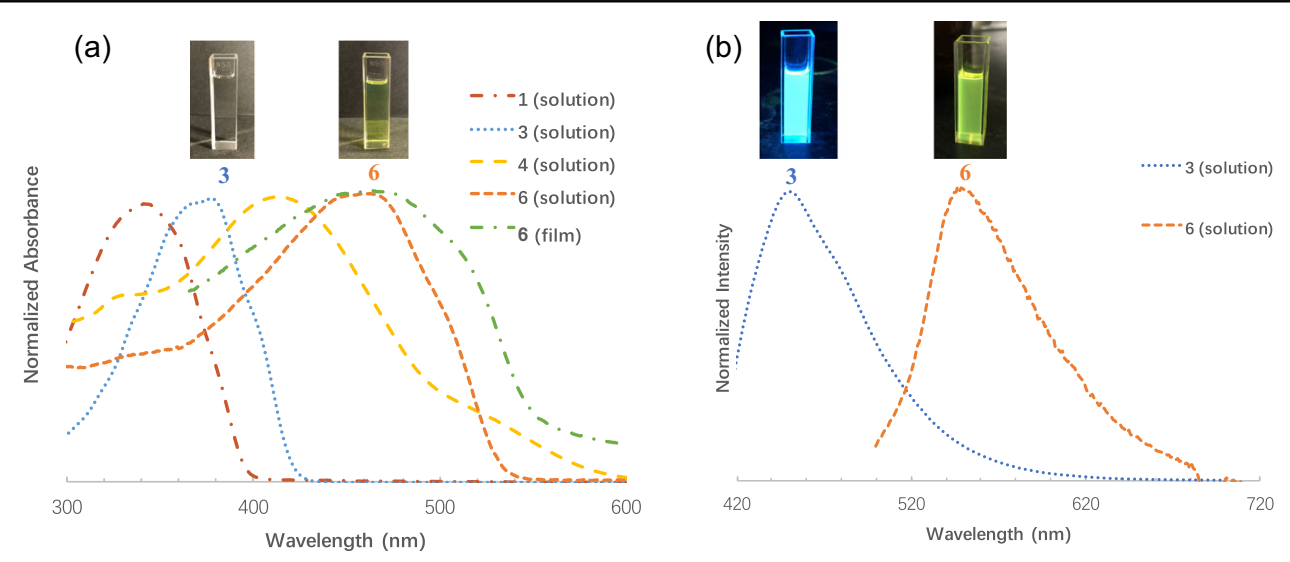

Fig. 2 UV-vis and PL spectra of tellurophene and germole derivatives and polymers containing the corresponding units. a UV-vis spectra of $\mathbf{1}, \mathbf{3}, \mathbf{4}$, and $\mathbf{6}$ in THF. $\mathbf{b}$ PL spectra of $\mathbf{3}$ and $\mathbf{6}$ in THF.

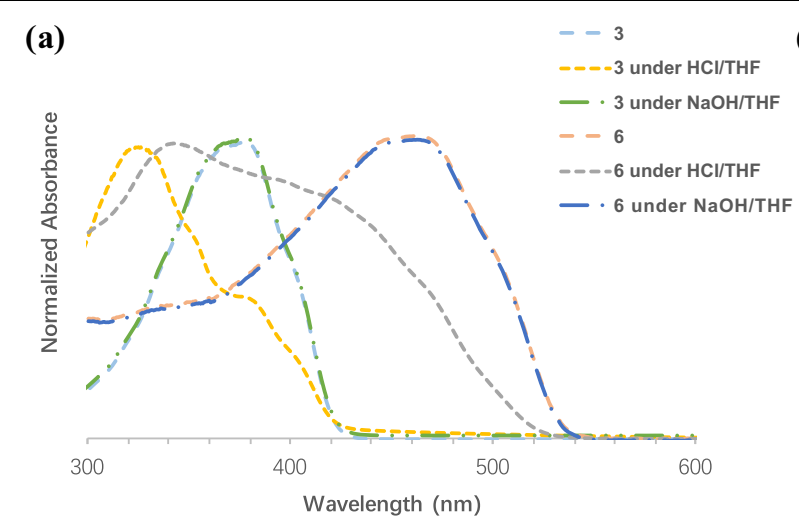

(b)

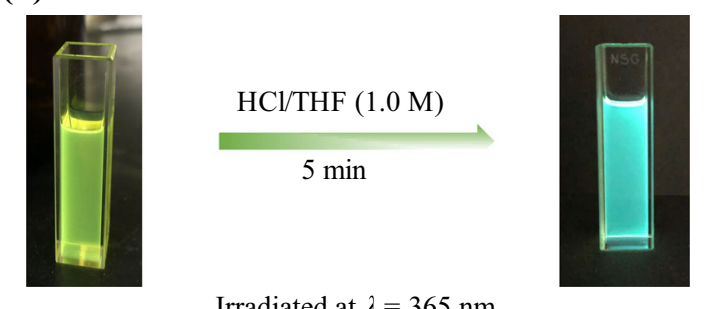

Irradiated at $\lambda=365 \mathrm{~nm}$

Fig. 3 Stability of a germole derivative and a germole-containing polymer under basic and acidic conditions as monitored by the changes of the UV-vis spectra and photoluminescence properties. a UV-vis spectra of $\mathbf{3}$ and $\mathbf{6}$ before and after mixing their THF solutions with aqueous $\mathrm{NaOH}(1.0 \mathrm{M})$ solutions or aqueous $\mathrm{HCl}(1.0 \mathrm{M})$ solutions at ambient temperature for $4 \mathrm{~h}$ under air. $\mathbf{b}$ Fluorescence color change of $\mathbf{6}$ upon treatment with aqueous $\mathrm{HCl}(1.0 \mathrm{M})$ solution in $\mathrm{THF}$ at ambient temperature for $5 \mathrm{~min}$.

diphenylsilole $(-5.64 \mathrm{eV})$, probably due to the lower electron affinity of Ge than of $\mathrm{Si}^{25}$. Likewise, the electrochemical properties of $\mathbf{6}$ were evaluated from the CV analysis in the film state (Fig. S6). The HOMO and LUMO energy levels of 6 were estimated to be -5.83 and $-3.65 \mathrm{eV}$, respectively. It is of note that the LUMO energy level of $\mathbf{6}$ is lower than that of the group 16 elementcontaining polymers, such as the thiophene-containing polymer $(\mathrm{LUMO}=-3.16 \mathrm{eV})$, and almost comparable to that of the group 15 element-containing polymers, such as the phosphole-containing polymers $(\mathrm{LUMO}=-3.60 \mathrm{eV})$, that were obtained from the same organotitanium polymer (Table 1$)^{26}$. These results indicate that group 14 and 15 elements have a strong ability to reduce the LUMO energy levels, most likely due to $\sigma^{*}-\pi^{*}$ orbital interactions. The presence of the $\sigma^{*}-\pi^{*}$ interaction was supported by the DFT calculation of a simple model compound, 1,1-dimethylgermole (Fig. S8).

\section{Interaction with fluoride}

The UV-vis spectra of 6 and $3\left(1.0 \times 10^{-5} \mathrm{M}\right)$ were obtained in the presence of tetrabutylammonium fluoride (TBAF). The absorption peak intensity increased as a function of the concentration of fluoride, although the variation in the spectra might include any unexpected changes, as the spectra do not exhibit clear isosbestic points (Figs. 4 and S9). The PL spectra of 3 and $\mathbf{6}(1.0 \times$ $\left.10^{-5} \mathrm{M}\right)$ were also taken in the presence of TBAF $(0.50 \mathrm{M})$ (Fig. S10). There are no distinct changes in the PL spectra, while the quantum yields of $\mathbf{3}$ and $\mathbf{6}$ decreased from 0.33 to 0.17 and from 0.04 to 0.02 , respectively. In addition, the peak of the methyl substituent on the germanium atom exhibited a clear high magnetic field shift in the ${ }^{1} \mathrm{H}$ NMR spectrum (Fig. S11). These results may indicate that the germanium atoms form hypervalently coordinated species, as are often reported for group 14 elements, such as $\mathrm{Si}, \mathrm{Ge}$, and $\mathrm{Sn}^{27,28}$. 
Table 1 Optical and electronic properties of 3 and 6.

\begin{tabular}{|c|c|c|c|c|c|c|c|c|}
\hline Compounds & $\lambda_{\max }(\mathrm{nm})^{\mathrm{a}}$ & $\lambda_{\text {onset }}(\mathrm{nm})^{\mathrm{b}}$ & $E_{\mathrm{g}}(\mathrm{opt})(\mathrm{eV})^{\mathrm{c}}$ & $E_{\max }(\mathrm{nm})^{\mathrm{d}}$ & $\Phi^{\mathrm{e}}$ & $E_{\text {ox }}(\mathrm{eV})$ & HOMO $(\mathrm{eV})^{\mathrm{h}}$ & LUMO $(\mathrm{eV})$ \\
\hline $3\left(\mathrm{CHCl}_{3}\right.$ solution $)$ & 379 & 413 & 3.00 & 454 & 0.33 & $1.10^{f}$ & -5.50 & -2.50 \\
\hline $6\left(\mathrm{CHCl}_{3}\right.$ solution $)$ & 465 & 535 & 2.31 & 547 & 0.04 & - & - & - \\
\hline 6 (Film) & 475 & 570 & 2.18 & - & - & $1.03^{\mathrm{g}}$ & -5.83 & -3.65 \\
\hline
\end{tabular}

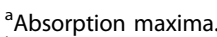

${ }^{\mathrm{b}}$ Absorption onsets.

'Optical energy band gap, estimated from $\lambda_{\text {onset. }}$.

dEmission maxima, irradiated at their $\lambda_{\text {max }}$.

'The quantum yields $(\Phi)$, estimated at ambient temperature.

fOnset potential of oxidation, estimated from cyclic voltammetric analysis (in MeCN, SCE as a reference electrode).

${ }^{9}$ Onset potential of oxidation, estimated from cyclic voltammetric analysis (in film, $\mathrm{Ag} / \mathrm{AgCl}$ as a reference electrode).

$\left.{ }^{h} \mathrm{HOMO}\right)=-\left(E_{\mathrm{ox}}+4.40\right)(\mathrm{eV})$.

${ }^{\mathrm{i}} E(\mathrm{LUMO})=E(\mathrm{HOMO})+E_{\mathrm{g}}(\mathrm{opt})(\mathrm{eV})$.

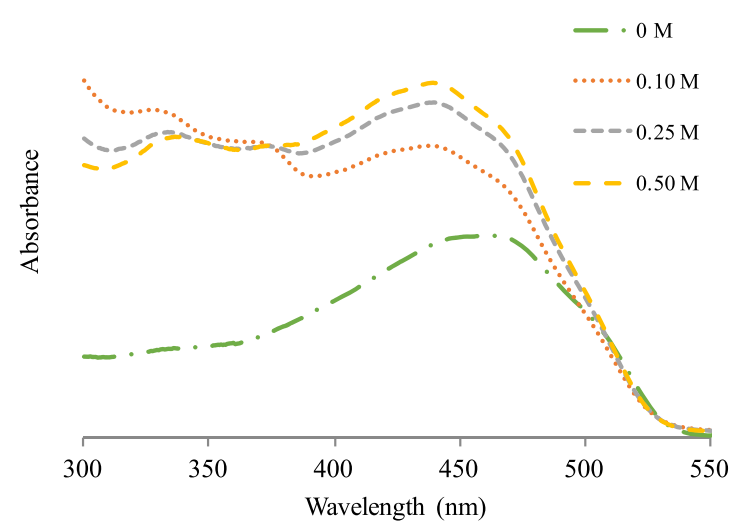

Fig. 4 UV-vis spectra of 6 with varied concentrations of TBAF. The spectra were taken in the presence of TBAF $(0 \mathrm{M}, 0.10 \mathrm{M}, 0.25 \mathrm{M}$, and $0.50 \mathrm{M})$

\section{Conclusions}

In summary, a $\pi$-conjugated polymer possessing geromole repeating units was prepared by the $\mathrm{Te}-\mathrm{Li}$ exchange reaction of a regioregular $\pi$-conjugated polymer containing tellurophene units in the main chain. The extension of the $\pi$-conjugation along the polymer backbone was supported by its UV-vis absorption spectrum. The germole-containing polymer proved to have a lower LUMO energy level than the thiophene-containing and phosphole-containing polymers obtained via the same organotitanium polymers, reflecting the strong electron-accepting nature of the 1,1-dimethylgermole unit. The germole-containing $\pi$-conjugated polymer exhibits green photoluminescence in a chloroform solution. The ability of the germole-containing $\pi$-conjugated polymer to act as a fluoride chemosensor was also demonstrated by the deviation of the UV-vis absorption spectra.

Since the present method is suitable for the versatile macromolecular design of $\pi$-conjugated germole- containing polymers and the germole-containing polymer exhibits interesting optoelectronic features, applications of the present synthetic method to produce materials for organic devices such as OLEDs and OSCs are in progress.

\section{Acknowledgements}

This work was supported by a Grant-in-Aid for Scientific Research on Innovative Areas "New Polymeric Materials Based on Element-Blocks (No. 2401)" (24102007) from The Ministry of Education, Culture, Sports, Science, and Technology, Japan.

Conflict of interest

The authors declare that they have no conflict of interest.

Publisher's note

Springer Nature remains neutral with regard to jurisdictional claims in published maps and institutional affiliations.

Supplementary information is available for this paper at https://doi.org/ 10.1038/s41427-020-0224-9.

Received: 24 January 2020 Revised: 19 March 2020 Accepted: 22 March 2020.

Published online: 5 June 2020

\section{References}

1. Grimsdale, A. C., Chan, K. L., Martin, R. E., Jokisz, P. G. \& Holmes, A. B. Synthesis of light-emitting conjugated polymers for applications in electroluminescent devices. Chem. Rev. 109, 897-1091 (2009).

2. Günes, S., Neugebauer, H. \& Sariciftci, N. S. Conjugated polymer-based organic solar cells. Chem. Rev. 107, 1324-1388 (2007).

3. Numazawa, H., Sato, K. Imai, H. \& Oaki, Y. Multistage redox reactions of conductive-polymer nanostructures with lithium ions: potential for highperformance organic anodes. NPG Asia Mater. 10, 397-405 (2018).

4. Lee, H. S. et al. Effect of donor-acceptor molecular orientation on charge photogeneration in organic solar cells. NPG Asia Mater. 10, 469-481 (2018).

5. Salzner, U., Lagowski, J. B., Pickup, P. G. \& Poirier, R. A. Comparison of geometries and electronic structures of polyacetylene, polyborole, polycyclopentadiene, polypyrrole, polyfuran, polysilole, polyphosphle, polythiophene, polyselenophene and polytellurophene. Synth. Met. 96, 177-189 (1998).

6. Yamaguchi, S. \& Tamao, K. Cross-coupling reactions in the chemistry of silolecontaining $\pi$-conjugated oligomers and polymers. J. Organomet. Chem. 653, 223-228 (2002). 
7. Wang, F., Luo, J., Chen, J. W., Huang, F. \& Cao, Y. Conjugated random and alternating 2,3,4,5-tetraphenylsilole-containing polyfluorenes: synthesis, characterization, strong solution photoluminescence, and light-emitting diodes. Polymer 46, 8422-8429 (2005).

8. Linshoeft, J. et al. Highly Tin-selective Stille coupling: synthesis of a polymer containing a stannole in the main chain. Angew. Chem. Int. Ed. 53 12916-12920 (2014)

9. Matsumura, Y. et al. Synthesis of stannole-containing $\pi$-conjugated polymers by post-element transformation of organotitanium polymer. Macromol. Rapid Commun. 40, 1800929 (2019).

10. Yamaguchi, S., Itami, Y. \& Tamao, K. Group 14 metalloles with thienyl groups on 2, 5-positions: effects of group 14 elements on their $\pi$-electronic structures. Organometallics 17, 4910-4916 (1998).

11. Lucht, B. L., Buretea, M. A. \& Tilley, T. D. Poly (2, 5-diphenylgermole): incorporation of a germole ring into a conjugated polymer. Organometallics 19 3469-3475 (2000).

12. Spivey, A. C., Turner, D. J., Turner, M. L. \& Yeates, S. A tuneable Ge-based linker that enables application-led solid phase synthesis optimisation - towards a robust iterative synthesis of oligothiophenes. Synlett 1, 0111-0115 (2004).

13. Spivey, A. C. et al. Light-fluorous safety-catch arylgermanes-exceptionally robust, photochemically activated precursors for biaryl synthesis by $\mathrm{Pd}(0)$ catalysed cross-coupling. Chem. Commun. 28, 2926-2928 (2007).

14. Atami, K., Kino, T., Zhou, W. M., Nishiyama, H. \& Tomita, I. Synthesis of $\pi-$ conjugated polymers possessing 1,3-butadiene-1,4-diyl units by reactions of regioregular organometallic polymer having titanacyclopentadiene moieties in the main chain. Synth. Met. 159, 949-951 (2009).

15. Kino, T., Nishiyama, H. \& Tomita, I. Synthesis of $\pi$-conjugated polymers via regioregular organometallic polymers 2 . Transformation of titanacyclopentadiene-containing polymer into poly(p-phenylene) derivative. Appl. Organomet. Chem. 24, 558-562 (2010).

16. Nishiyama, H. \& Tomita, I. Synthesis of $\pi$-conjugated polymer possessing mercapto-substituted 1,3-butadiene-1,4-diyl units by reaction of regioregular organometallic polymer having titanacyclopentadiene moieties in the main chain. Macromol. Chem. Phys. 20, 2248-2253 (2010).
17. Nishiyama, H., Kino, T. \& Tomita, I. Transformation of regioregular organotitanium polymers into group 16 heterole-containing $\pi$-conjugated materials. Macromol. Rapid Commun. 33, 545-549 (2012).

18. Matsumura, Y. et al. Synthesis of $\pi$-conjugated polymers containing phosphole units in the main chain by reaction of an organometallic polymer having a titanacyclopentadiene unit. ACS Macro Lett. 4, 124-127 (2015).

19. Matsumura, Y. et al. Arsole-containing $\pi$-conjugated polymer by the postelement-transformation technique. Angew. Chem. Int. Ed. 55, 15040-15043 (2016).

20. Tomita, I. et al. Low band gap $\pi$-conjugated polymers containing versatile elements-blocks. Presented at the 247th ACS National Meeting and Exposition (Dallas, TX, 2014).

21. Katkevics, M., Yamaguchi, S., Toshimitsu, A. \& Tamao, K. From tellurophenes to siloles. synthesis, structures, and photophysical properties of 3,4-unsubstituted 2,5-diarylsiloles. Organometallics 17, 5796-5800 (1998).

22. Zheng, F. et al. Te-Li exchange reaction of tellurophene-containing $\pi$-conjugated polymer as potential synthetic tool for functional $\pi$-conjugated polymers. Macromol. Rapid Commun. 40, 1900171 (2019).

23. Frisch, M. J. et al. Gaussian 16, Revision A. 03 (Gaussian, Inc., Wallingford CT, 2016).

24. Liu, D. X. et al. Extended conjugation length of nonfullerene acceptors with improved planarity via noncovalent interactions for high-performance organic solar cells. Adv. Energy Mater. 8, 1801618 (2018).

25. Masahiro, K., Hideki, T. \& Nakadaira, Y. Electron-transfer reaction of 1,2-disila-3,5cyclohexadienes. Tetrahedron Lett. 38, 3525-3528 (1997).

26. Matsumura, Y., Fukuda, K., Inagi, S. \& Tomita, I. Parallel synthesis of photoluminescent $\pi$-conjugated polymers by polymer reactions of an organotitanium polymer with a titanacyclopentadiene unit. Macromol. Rapid Commun. 36, 660-664 (2015)

27. Timms, R. E. Five-co-ordinate silicon. Kinetics of the acid-catalysed hydrolysis of nitrilotriphenoxysilanes. J. Chem. Soc. A. 0, 1969-1974 (1971).

28. Gustavson, W. A., Principe, L. M., Rhee, W.-Z. M. \& Zuckerman, J. J. Synthesis of tetraphenylstannacyclopentadienes (stannoles). 2. Derivatives and adducts of 1,1-dihalo-2, 3, 4, 5-tetraphenylstannoles. Inorg. Chem. 20, 3460-3468 (1981). 